\title{
Effectiveness of methylphenidate and PUFA for the treatment of patients with ADHD: A double-blinded randomized clinical trial
}

\author{
Mahbobeh Firouzkouhi Moghaddam ${ }^{1}$, Maryam Shamekhi' ${ }^{2}$ Tayebeh Rakhshani ${ }^{3}$
}

${ }^{1}$ M.D. of Psychiatry, Assistant Professor, Research Center for Children and Adolescent Health, Department of Children and Adolescent Psychiatry, Zahedan University of Medical Science, Zahedan, Iran

${ }^{2}$ M.D., Assistant of Psychiatry, Department of Children and Adolescent Psychiatry, Zahedan University of Medical Science, Iran

${ }^{3}$ M.D., Assistant Professor of Health Education \& Promotion, Nutrition Research Center, Department Of Public Health, School of Health, Shiraz University of Medical Science, Iran

\section{Type of article: Original}

\begin{abstract}
Background: In some children with ADHD, sub-optimal levels of various nutrients including PUFA especially omega-3 has been observed, and contradictory reports exist on the results of studies conducted on the positive therapeutic effects of PUFA in patients with ADHD.

Objective: The aim of this study was to investigate the effectiveness of methylphenidate and PUFA on treatment of patients with ADHD in Zahedan, Iran.

Methods: In this clinical trial, 40 children between 6 and 12 years of age with ADHD were investigated in Zahedan in 2014. Patients were randomly divided into two groups of methylphenidate plus PUFA and methylphenidate plus placebo. ADHD rating scale was filled before and after the study for patients of both groups. Finally, data were analyzed using SPSS18, paired-samples t-test and chi-square.

Results: Mean age of patients was $2.9 \pm 1.8$ years. Thirty-three children $(82.5 \%)$ were boys and seven children $(17.5 \%)$ were girls. Mean severity of signs in the group under methylphenidate plus PUFA treatment was $39.9 \pm 4.9$ before treatment and $20.1 \pm 6.0$ after 8 weeks of treatment $(p<0.001)$. Mean severity of signs in the group under methylphenidate plus placebo treatment was $41.2 \pm 2.7$ before treatment and $26.1 \pm 9.0$ after 8 weeks of treatment $(p<0.001)$. Mean reduction in the severity of symptoms in the group under methylphenidate therapy was 19.7 \pm 5.9 and in PUFA and placebo group it was $15.1 \pm 9.3(\mathrm{p}<0.067)$. Response to treatment (a reduction of at least $25 \%$ in the signs) in the group taking methylphenidate plus PUFA was $90 \%$ (18 patients) and in methylphenidate plus placebo group, it was $60 \%$ (12 patients) $(\mathrm{p}=0.028)$.

Conclusion: This study shows that PUFA is an efficient nutrient to treat ADHD and it can be used to treat patients. However, definitive conclusion requires repeating the study with a larger sample and longer study period.
\end{abstract}

Trial registration: The trial was registered at the Iranian Registry of Clinical Trials (http://www.irct.ir) with the Irct ID: IRCT2015092724209N2.

Funding: The authors received no financial support for the research, authorship, and/or publication of this article.

Keywords: Methylphenidate; Attention Deficit/Hyperactivity Disorder; Unsaturated Fatty Acids

\section{Introduction}

ADHD (Attention Deficit/Hyperactivity Disorder) is a disease that despite being identified, its genetic background is not yet clear (1-3). This disease keeps children and adolescents in a state of failure and socially retarded condition. Although it mostly affects boys, it has been seen in girls too (4). About the pathology of ADHD, it has been stated that the noradrenergic system, including the central system (locus coeruleus) and peripheral sympathetic play a role

\section{Corresponding author:}

Dr. Tayebeh Rakhshani, Nutrition Research Center, Department Of Public Health, School of Health, Shiraz University of Medical Science, Iran. Tel: +98.919-6250473, Fax:+98.713-7260225, Email: trakhshani@gmail.com Received: March 12, 2016, Accepted: August 16, 2016, Published: May 2017 iThenticate screening: August 03, 2016, English editing: March 20, 2017, Quality control: April 02, 2017

(C) 2017 The Authors. This is an open access article under the terms of the Creative Commons Attribution-NonCommercialNoDerivs License, which permits use and distribution in any medium, provided the original work is properly cited, the use is non-commercial and no modifications or adaptations are made. 
in it (5-7). The peripheral sympathetic system plays a more prominent role in prevalence of ADHD symptoms such that a disorder occurs in the peripheral epinephrine and it causes the locus coeruleus to be regulated at a lower level (6). Although in many studies, epinephrine and norepinephrine levels, or their metabolites in ADHD children's plasma or urine has increased relative to control group, (5-8) there are no constant findings in review studies that indicate the decrease or lack of any changes in environmental levels of monoamines or their metabolites. Considering the role of the central noradrenergic system and peripheral automatic sympathetic system in arousal state, and considering the noradrenergic effects of stimulant drugs, this theory formed that the noradrenergic system plays a role in ADHD (9-12). Of other physiologic disorders, available in this disease is the reduced response of the adrenaline moderator (5). This reduced response exists while conducting cognitive tests and even when hypoglycemia occurs, that shows a state called reduced response of epinephrine (13). This reduced response can probably be justified by the increase in peripheral epinephrine as the hypothesis stated in the etiology of ADHD explained before. Of the most common treatments for this disorder are the stimulant drugs including methylphenidate $(5-7,14)$. By facilitating the release of catecholamines in the locus coeruleus and controlling their resorption in the cell synapses, stimulant drugs increase the level of these materials and then reduce the symptoms $(5,8,14)$. ADHD entails three subgroups of impulsivity hyperactivity overcome, attention deficit overcome and the mixed type. The effect of medicinal and non-medicinal therapies has been confirmed in this disorder. Methylphenidate is the most common drug, the effect of which has been verified on all three domains of ADHD symptoms (15-17). Response to this drug is different from 25 to 78 percent (18). Stimulant drugs are the major medicinal treatment for ADHD. Side effects of these drugs, including tic, irritability, anorexia along with their short effect ( 3 to 4 hours) makes it necessary to find alternative treatment methods with fewer side effects or adjuvant medicine to have the residual symptoms (19). In recent years, particular attention has been paid to PUFA (polyunsaturated fatty acid) which include omega-3 and omega-4 fatty acids (20-23). Some studies have shown that children with ADHD have unnatural amounts of PUFA especially reduced plasma concentration of arachidonic acid, docosahexaenoic acid (DHA), and eicosapentaenoic acid (EPA) (22-25). EFA discharge affects the brain with a high amount of fat and the need for n-3 PUFA for growth, connection, and function. DHA plays a major role in the development of the brain, while EPA is mostly important for performance (26-31). Considering that in many children with ADHD suboptimal levels of nutrients including PUFA, especially omega-3 has been reported and omega-3 is an unsaturated fatty acid, which is one of the components of the brain and neurotransmitters and its low blood levels in patients with ADHD. In addition, its being efficient and lack of complications has been verified in previous studies. Considering proper dosage and the type of PUFA used is not fully identified in ADHD, papers have recommended to conduct more studies with various dosages of PUFA and applying various types of PUFA (omega-3 and omega-4 alone or along with each other). Since there are contradictory reports on the results of conducted studies on the positive effect of PUFA in patients with ADHD, we decided to conduct a study to investigate the therapeutic effect of PUFA as an adjuvant therapy in children with ADHD in Zahedan.

\section{Material and Methods}

\subsection{Trial Design}

This clinical trial was conducted on 40 children of 6 to 12 years of age diagnosed with ADHD referring to state and private clinics in Zahedan in 2014.

\subsection{Sampling}

Samples were selected among parents referring outpatient clinics using random sampling. Sample size was selected to be 40 patients considering confidence interval of $95 \%$ and alpha of 0.05 .

\subsection{Inclusion Criteria}

In this study, inclusion criteria were obtaining the least score in an ADHD rating scale questionnaire, responding to the treatment based on least reduction of $25 \%$ of symptoms relative to the base state in ADHD scaling. Exclusion criteria were: Any type of concurrent major psychological disease except oppositional defiant disorder (ODD) and learning disorder (OD), intelligence quotient below 70, taking psychedelic drugs or drugs in two recent weeks, any major neurological disease and taking any drug affecting the nervous system at least two weeks before the study.

\subsection{Intervention and Data Collection}

Next, a form of demographic data was filled for each child separately. Before starting treatment, participants were physically examined especially in terms of weight, heart rate, and blood pressure. In addition, diagnostic questionnaire of ADHD rating scale was filled for children at this time. Parents' form of this scale was filled by one of the parents. Patients were randomly divided into two groups using a random numbers table. In the first group, 
treatment with $0.3 \mathrm{mg} / \mathrm{kg}$ methylphenidate per day was started twice a day and it reached $1 \mathrm{mg} / \mathrm{kg}$ within two weeks. Treatment with omega-3 capsules containing 180mg EPA and $120 \mathrm{mg}$ DHA was started concurrently. In 2, 4, 6, and 8 weeks of treatment, ADHD rating scale questionnaire was again filled by the resident of psychiatry for patients of both groups. Data related to side effects were collected via interviewing patients and their parents as well as the therapist observations according to the inventory of drugs side effects.

\subsection{Randomization and Blinding}

During the study, the prescriber and patient rater were not aware of the type of prescribed medicine and they were different. For the study being double blinded, patients were divided into placebo and PUFA groups randomly by the author and were referred to via a code to the person in charge of drug distribution. In addition, methylphenidate and PUFA were taken to the patients in pre-prepared envelopes based on code 1 and 2. Considering the special PUFA form that is typically in capsules, its placebo was prepared and was taken to the other group to prevent drug takers from noticing the patient rater of their used drugs.

\subsection{Statistical Methods}

Data analysis was conducted using the SPSS18 statistical software. Numerical variables were presented as mean (SD), whereas nominal and categorized variables were summarized by absolute frequencies and percentages. To compare the baseline measurements between the two groups, chi-square test and paired-samples t-test were used.

\subsection{Research Ethics}

This study has been conducted, based on a residency thesis to the number 6752 in the ethics committee, and supported by Deputy of Research and Technology of Zahedan University of Medical Sciences. In this study, codes 8 and 17 approved by the national ethics committee in medical studies have been observed. After selecting patients and being given parents' consent, method and objectives of conducting this study were explained for them.

\section{Results}

Mean age of children receiving methylphenidate and PUFA (treatment group) was $9.5 \pm 2.0$ and in children receiving methylphenidate and placebo (control group), it was $8.9 \pm 1.6(\mathrm{p}=0.387)$. Of these patients, thirty-three children $(82.5 \%)$ were boys and seven children $(17.5 \%)$ were girls. $(p=0.212)$. In this study, mean severity of symptoms in the group under treatment of methylphenidate plus PUFA before and after 8 weeks of treatment for attention deficit type (before: $20.9 \pm 3.4$ and after: $10.4 \pm 3.5$ ), for predominantly impulsive-hyperactive type (before: $18.9 \pm 4.3$ and after: 9.7 \pm 4.6 ), and for the mixed type (before: $39.8 \pm 4.9$ and after: $20.1 \pm 6.0$ ). In addition, mean severity of symptoms in the group under treatment of methylphenidate plus supplement before and after 8 weeks of treatment for attention deficit type (before: $20.5 \pm 2.9$ and after: 13.2 \pm 5.9 ), for predominantly impulsive-hyperactive type (before: $20.5 \pm 2.9$ and after: $13.2 \pm 5.2$ ), and for the mixed type (before: $41.2 \pm 2.7$ and after: $26.1 \pm 9.0)(p<0.001)$ (Table 1). Mean severity of symptoms after treatment in the treatment group was significant relative to the placebo group. $(\mathrm{p}<0.05)$ (Table 2$)$. The most common side effects related to methylphenidate in the treatment group were sleep disorders, anorexia, headache and dizziness, and depression and in placebo group, they were sleep disorders, abdominal pain, dizziness and restlessness. The most common side effects of methylphenidate in both groups were sleep disorders and anorexia and no significant difference was observed in both groups ( $\mathrm{p}>0.05)$. PUFA side effect was just one case of burping.

Table 1. A comparison between the mean severity of symptoms before and after the treatment in the treatment and placebo groups

\begin{tabular}{|l|l|l|l|l|}
\hline Group & Type of symptoms & Pre-intervention & Post-intervention & $p$-value \\
\hline \multirow{4}{*}{ Treatment } & Predominantly attention deficit & $4.9 \pm 3.20$ & $5.3 \pm 4.1$ & $<0.001$ \\
\cline { 2 - 5 } & Predominantly impulsive - hyperactive & $3.4 \pm 9.18$ & $6.4 \pm 7.9$ & $=0.01$ \\
\cline { 2 - 5 } & mixed & $9.4 \pm 8.39$ & $0.6 \pm 1.20$ & $<0.001$ \\
\hline \multirow{3}{*}{ Placebo } & Predominantly attention deficit & $8.2 \pm 7.20$ & $7.3 \pm 9.12$ & $<0.001$ \\
\cline { 2 - 5 } & Predominantly impulsive - hyperactive & $9.2 \pm 5.20$ & $9.5 \pm 2.13$ & $<0.001$ \\
\cline { 2 - 5 } & Mixed & $7.2 \pm 2.41$ & $0.9 \pm 1.26$ & $<0.001$ \\
\hline
\end{tabular}


Table 2. A comparison between the mean severity of symptoms in the intervention and control groups after the treatment

\begin{tabular}{|l|l|l|l|}
\hline Type of symptoms & Intervention & Placebo & $p$-value \\
\hline Predominantly attention deficit & $5.3 \pm 4.1$ & $7.3 \pm 9.12$ & 0.34 \\
\hline Predominantly impulsive - hyperactive & $6.4 \pm 7.9$ & $9.5 \pm 2.13$ & 0.34 \\
\hline Mixed & $1.20 \pm 0.6$ & $0.9 \pm 1.26$ & 0.18 \\
\hline
\end{tabular}

\section{Discussion}

Results of this study showed that mean severity of symptoms before treatment in both groups of methylphenidate plus PUFA and placebo was the same, and severity of symptoms after treatment in the group under methylphenidate plus PUFA treatment had reduced much more compared to the placebo group, and major changes were observed in the subscale of predominantly attention deficit type. A significant difference was observed in the analysis of the percentage of people who showed reduced severity of symptoms for $25 \%$ compared to those who showed the same rate of reduction using methylphenidate plus placebo $(90 \%$ vs. $60 \%)$ and this shows the effect of PUFA in reducing the severity of symptoms compared to placebo. In other words, adding PUFA to placebo resulted in better response of ADHD patients to methylphenidate, and increased the number of people who responded to this drug. In this study, the concurrent use of PUFA resulted in improved attention or mobility in children with ADHD and this was similar to some previous studies in this field. For example, as mentioned earlier, in the study conducted by Bélanger et al. in 2009, it was concluded that supplement n-3 PUFA can be useful in a subgroup of children with ADHD (especially in the attention deficit subscale) and these drugs are well-tolerated by children (32). In addition, in the studies conducted by Richardson et al. between 2004 and 2006 in England, a marked improvement was observed in major symptoms of ADHD and they stated that omega-3 fatty acids show better effects in treatment of behavior and learning problems of children with ADHD compared to omega-6 fatty acids (33-35). In a study conducted by Gustafsson et al. in 2010, results showed that in two subgroups of children with ADHD (including children with oppositional defiant disorder and less active children), improvement was observed after 15 weeks of treatment, and increased concentration of EPA and reduced concentration of omega- 6 fatty acids in phospholipids was related to clinical improvement (36). However, some studies are conducted in this field the results of which are contrary to the results of our study, including the study by Gillies et al. in 2012 who showed that prescribing PUFA supplement is not useful in improvement of ADHD symptoms in children and adolescents (37). In a study conducted by Laasonen et al. in 2009, the general ratio of n-6 PUFA (including gamma-linoleic acid) in patients with ADHD was higher compared to patients without this disorder, and after controlling reading problems, education and the quality of fat in diet or using supplement fatty acids usually created no changes in the conditions (38). In the study by $\mathrm{Ng}$ et al. in 2009, it was shown that although the use of fish and sea food, meat and egg was half in children with ADHD compared to control group, there was no relation between symptoms of ADHD and fatty acids (39). In addition, in a review study conducted by Raz and Gabis in 2009, the effectiveness of adding fatty acids to the diet was not observed in increasing the blood level and improvement of ADHD symptoms, and these authors did not recommend using these fatty acids as the main or adjuvant therapy in children with ADHD (40). One of the reasons for different results in studies is the measuring time of the effect of the drug that can have a significant effect on the findings of the study. In some studies, it has been stated that the minimum time required for PUFA efficiency is three months. This study was also conducted within 3 months (12 weeks). Lack of prevalent effect when adding PUFA to methylphenidate in some studies can be due to the short time of study, and longer treatment can increase efficiency. Similar to the study by Hirayama in 2004 that was conducted in Japan for 2 months, no improvement was observed in symptoms of ADHD in a group receiving DHA and in return, improvement of symptoms in the control group was better (41). However, in a study conducted by Sinn and Bryan in 2007 in Australia, within 30 weeks, the medium to strong positive effect was observed in the Conners' Parent Rating Scale in groups receiving PUFA (42). Assorted types of fatty acids available in the diet of children with ADHD is another topic addressed in some research (39). Considering cultural differences available in the diet of various nations, the difference between our study and other studies on inefficiency of adding PUFA to the diet of children with ADHD may be due to different composition of diets in terms of PUFA content (for example, its being sufficient in the diet of children receiving placebo and its becoming inefficient when being added as drug) that could in return justify the differences in the results of various studies. Considering the conditions of the area under study and low food security of this region, the effect of diet therapy used in this research could be justified. Another factor that can create some changes in the results of this study with other studies is the differences available in dosage of PUFA used in various studies. These differences and lack of a standard dosage of PUFA can be a cause of variations observed in results of this study with other studies. 


\section{Conclusions}

This study showed that concurrent use of PUFA improved the attention state of children with ADHD and considering different composition of diets in terms of PUFA content, in turn can justify the differences existing in results of various studies considering the area conditions. Therefore, it was suggested to design and conduct more clinical trials with larger sample size and a longer period in other regions to assess patients with ADHD.

\section{Acknowledgments:}

This study was designed and extracted from a thesis submitted at Zahedan University of Medical Sciences. Hereby, the authors appreciate all people and families with ADHD children, who participated this study.

\section{Conflict of Interest:}

There is no conflict of interest to be declared.

\section{Authors' contributions:}

All authors contributed to this project and article equally. All authors read and approved the final manuscript.

\section{References:}

1) Qiu J, Hong Q, Chen RH, Tong ML, Zhang M, Fei L, et al. Gene expression profiles in the prefrontal cortex of SHR rats by cDNA microarrays. Mol Biol Rep. 2010; 37(4): 1733-40. doi: 10.1007/s11033-0099596-1. PMID: 19572212.

2) Wei JL, Bond J, Mayo MS, Smith HJ, Reese M, Weatherly RA. Improved behavior and sleep after adenotonsillectomy in children with sleep-disordered breathing: long-term follow-up. Arch Otolaryngol Head Neck Surg. 2009; 135(7): 642-6. doi: 10.1001/archoto.2009.74. PMID: 19620583.

3) Joo EJ, Greenwood TA, Schork N, McKinney RA, Sadovnick AD, Remick RA, et al. Suggestive evidence for linkage of ADHD features in bipolar disorder to chromosome 10p14. Am J Med Genet B Neuropsychiatr Genet. 2010; 153B(1): 260-8. doi: 10.1002/ajmg.b.31005. PMID: 19603423.

4) American Academy of Pediatrics. Clinical practice guideline: diagnosis and evaluation of the child with attention-deficit/hyperactivity disorder. American Academy of Pediatrics. Pediatrics. 2000; 105(5): 115870. doi: 10.1542/peds.105.5.1158. PMID: 10836893.

5) Greenhill LL, Hechtman LI. Attention-Deficit/Hyperactivity Disorder. In: Sadock BJ, Sadock VA, Ruiz P.(eds). Comprehensive Text Book of Psychiatry. 9th ed. Philadelphia (PA): Lippincott, Williams \& Wilkins. 2009; 3560-72.

6) Sadock BJ, Sadock VA. Kaplan and Sadock's Synopsis of psychiatry, behavioral clinical psychiatry.10 th ed. Philadelphia (PA): Lippincott, Williams \& Wilkins. 2007; 1206-17.

7) Anderson GM, Martin A. Neurochemistry pharmacodynamic and biological psychiatry. Spetie L, Arnold LE. Attention-Deficit/Hyperactivity Disorder. In: Martin A, VolkmarFR. (eds). Lewis's Child and Adolescent Psychiatry: A Comprehensive Textbook, 4th ed. Philadelphia (PA): Lippincott, Williams \& Wilkins. 2007; 240- 3, 430-49.

8) Berridge $\mathrm{CW}$, Waterhouse $\mathrm{BD}$. The locus coeruleus-noradrenergic system: modulation of behavioral state and state-dependent cognitive processes. Brain Res Brain Res Rev. 2003; 42(1): 33-84. doi: 10.1016/S0165-0173(03)00143-7. PMID: 12668290.

9) Baker GB, Bornstein RA, Douglass AB, Van Muyden JC, Ashton S, Bazylewich TL. Urinary excretion of MHPG and normetanephrine in attention deficit hyperactivity disorder. Mol Chem Neuropathol. 1993; 18(1-2): 173-8. doi: 10.1007/BF03160031. PMID: 8466590.

10) Zametkin AJ, Rapoport JL. Neurobiology of attention deficit disorder with hyperactivity: where have wecome in 50 years? J Am Acad Child Adolesc Psychiatry. 1987; 26(5): 676-86. doi: 10.1097/00004583198709000-00011. PMID: 2889717.

11) Mefford IN, Potter WZ. A neuroanatomical and biochemical basis for attention deficit disorder with hyperactivity in children: a defect in tonic adrenaline mediated inhibition of locus coeruleus stimulation. Med Hypotheses. 1989; 29(1): 33-42. doi: 10.1016/0306-9877(89)90164-3. PMID: 2546021.

12) Pliszka SR, McCracken JT, Maas JW. Catecholamines in attention-deficit hyperactivity disorder: current perspectives. J Am Acad Child Adolesc Psychiatry. 1996; 35(3): 264-72. doi: 10.1097/00004583199603000-00006. PMID: 8714313.

13) Anderson GM, Dover MA, Yang BP, Holahan JM, Shaywitz SE, Marchione KE, et al. Adrenomedullary function during cognitive testing in attention-deficit/hyperactivity disorder. J Am Acad Child Adolesc Psychiatry. 2000; 39(5): 635-43. doi: 10.1097/00004583-200005000-00018. PMID: 10802982. 
14) Greydanus DE, Pratt HD, Patel DR. Attention deficit hyperactivity disorder across the lifespan: the child, adolescent, and adult. Dis Mon. 2007; 53(2): 70-131. doi: 10.1016/j.disamonth.2007.01.001. PMID: 17386306.

15) Wolraich M, Brown L, Brown RT, DuPaul G, Earls M, Feldman HM, et al. ADHD: clinical practice guideline for the diagnosis, evaluation, and treatment of attention-deficit/hyperactivity disorder in children and adolescents. Pediatrics. 2011; 128(5): 1007-22. doi: 10.1542/peds.2011-2654. PMID: 22003063, PMCID: PMC4500647.

16) Wilens TE. Effects of methylphenidate on the catecholaminergic system in attention-deficit/hyperactivity disorder. J Clin Psychopharmacol. 2008; 28(3 Suppl 2): S46-53. doi: 10.1097/JCP.0b013e318173312f. PMID: 18480677.

17) Watson SM, Richels C, Michalek AP, Raymer A. Psychosocial treatments for ADHD: a systematic appraisal of the evidence. J Atten Disord. 2015; 19(1): 3-10. doi: 10.1177/1087054712447857. PMID: 22647286.

18) Verma R, Balhara YP, Mathur S. Management of attention-deficit hyperactivity disorder. J Pediatr Neurosci. 2011; 6(1): 13-8. doi: 10.4103/1817-1745.84400. PMID: 21977081, PMCID: PMC3173906.

19) Weiss M, Weiss G. Attention Deficit Hyperactivity Disorder. In: Lewis M (ed). Child and adolescent Psychiatry. 3rd ed. Philadelphia: Lippincott Williams \&Wilkins. 2002: 645-65.

20) Williams CD, Whitley BM, Hoyo C, Grant DJ, Iraggi JD, Newman KA, et al. A high ratio of dietary n-6/n3 polyunsaturated fatty acids is associated with increased risk of prostate cancer. Nutr Res. 2011; 31(1): 1 8. doi: 10.1016/j.nutres.2011.01.002. PMID: 21310299.

21) Leitzmann MF, Stampfer MJ, Michaud DS, Augustsson K, Colditz GC, Willett WC, et al. Dietary intake of n-3 and n-6 fatty acids and the risk of prostate cancer. Am J ClinNutr. 2004; 80(1): 204-16. PMID: 15213050 .

22) Astorg P. Dietary N-6 and N-3 polyunsaturated fatty acids and prostate cancer risk: a review of epidemiological and experimental evidence. Cancer Causes Control. 2004; 15(4): 367-86. doi: 10.1023/B:CACO.0000027498.94238.a3. PMID: 15141138.

23) Burgess JR, Stevens L, Zhang W, Peck L. Long-chain polyunsaturated fatty acids in children with attention-deficit hyperactivity disorder. Am J Clin Nutr. 2000; 71(1Suppl): 327S-30S. PMID: 10617991.

24) Stevens LJ, Zentall SS, Abate ML, Kuczek T, Burgess JR. Omega-3 fatty acids in boys with behavior, learning, and health problems. Physiol Behav. 1996; 59(4-6): 915-20. doi: 10.1016/0031-9384(95)02207-4. PMID: 8778886.

25) Richardson AJ, Puri BK. The potential role of fatty acids in attention-deficit/hyperactivity disorder. Prostaglandins Leukot Essent Fatty Acids. 2000; 63(1-2): 79-87. doi: 10.1054/plef.2000.0196. PMID: 10970718.

26) Stevens LJ, Zentall SS, Deck JL, Abate ML, Watkins BA, Lipp SR, et al. Essential fatty acid metabolism in boys with attention-deficit hyperactivity disorder. Am J Clin Nutr. 1995; 62(4): 761-8. PMID: 7572706.

27) Brenna JT, Diau GY. The influence of dietary docosahexaenoic acid and arachidonic acid on central nervous system polyunsaturated fatty acid composition. Prostaglandins Leukot Essent Fatty Acids. 2007; 77(5-6): 247-50. doi: 10.1016/j.plefa.2007.10.016. PMID: 18023566, PMCID: PMC2174532.

28) McNamara RK, Carlson SE. Role of omega-3 fatty acids in brain development and function: Potential implications for the pathogenesis and prevention of psychopathology. Prostaglandins Leukot Essent Fatty Acids. 2006; 75(4-5): 329-49. doi: 10.1016/j.plefa.2006.07.010. PMID: 16949263.

29) Champeil-Potokar G, Chaumontet C, Guesnet P, Lavialle M, Denis I. Docosahexaenoic acid (22:6n-3) enrichment of membrane phospholipids increases gap junction coupling capacity in cultured astrocytes. Eur J Neurosci. 2006; 24(11): 3084-90. doi: 10.1111/j.1460-9568.2006.05185.x. PMID: 17156369.

30) Song C, Li X, Kang Z, Kadotomi Y. Omega-3 fatty acid ethyleicosapentaenoate attenuates IL-1betainduced changes in dopamine and metabolites in the shell of the nucleus accumbens: Involved with PLA2 activity and corticosterone secretion. Neuropsychopharmacology. 2007; 32(3): 736-44. doi: 10.1038/sj.npp.1301117. PMID: 16794572.

31) Song C, Horrobin D. Omega-3 fatty acid ethyl-eicosapentaenoate, but not soybean oil, attenuates memory impairment induced by central IL-1beta administration. J Lipid Res. 2004; 45(6): 1112-21. doi: 10.1194/jlr.M300526-JLR200. PMID: 15060086.

32) Frasure-Smith N, Lesperance F, Julien P. Major depression is associated with lower omega-3 fatty acid levels in patients with recent acute coronary syndromes. Biol Psychiatry. 2004; 55(9): 891-6. doi: 10.1016/j.biopsych.2004.01.021. PMID: 15110732 . 
33) Bélanger SA, Vanasse M, Spahis S, Sylvestre MP, Lippé S, L'heureux F, et al. Omega-3 fatty acid treatment of children with attention-deficit hyperactivity disorder: A randomized, double-blind, placebocontrolled study. Paediatr Child Health. 2009; 14(2): 89-98. PMID: 19436468, PMCID: PMC2661342.

34) Richardson AJ, Montgomery P. The Oxford-Durham Study: a randomized, controlled trail of dietary supplementation with fatty acids in children with developmental coordination-disorder. Pediatrics. 2005; 115(5): 1360-6. doi: 10.1542/peds.2004-2164. PMID: 15867048.

35) Richardson AJ. Omega-3 fatty acids in ADHD and related neurodevelopmetal disorders. Int Rev Psychiatry. 2006; 18(2): 155-72. doi: 10.1080/09540260600583031. PMID: 16777670.

36) Richardson AJ. Clinical trials of fatty acid treatment in ADHD, dyslexia, dyspraxia and autistic spectrum. Prostaglandins Leukot Essent Fatty Acids. 2004; 70(4): 383-90. doi: 10.1016/j.plefa.2003.12.020. PMID: 15041031.

37) Gustafsson PA, Birberg-Thornberg U, Duchén K, Landgren M, Malmberg K, Pelling H, et al. EPA supplementation improves teacher rated behaviour and oppositional symptoms in children with ADHD. Acta Paediatr. 2010; 99(10): 1540-9. doi: 10.1111/j.1651-2227.2010.01871.x. PMID: 20491709.

38) Gillies D, Sinn JKh, Lad SS, Leach MJ, Ross MJ. Polyunsaturated fatty acids (PUFA) for attention deficit hyperactivity disorder (ADHD) in children and adolescents. Cochrane Database Syst Rev. 2012; 7: CD007986. doi: 10.1002/14651858.cd007986.pub2. PMID: 22786509.

39) Laasonen M, Hokkanen L, Leppämäki S, Tani P, Erkkilä AT. Project DyAdd: Fatty acids in adult dyslexia, ADHD, and their comorbid combination. Prostaglandins Leukot Essent Fatty Acids. 2009; 81(1): 89-96. doi: 10.1016/j.plefa.2009.04.005. PMID: 19523794.

40) Ng KH, Meyer BJ, Reece L, Sinn N. Dietary PUFA intakes in children with attention-deficit/hyperactivity disorder symptoms. Br J Nutr. 2009; 102(11): 1635-41. doi: 10.1017/S0007114509990821. PMID: 19631022.

41) Raz R, Gabis L. Essential fatty acids and attention-deficit-hyperactivity disorder: a systematic review. Dev Med Child Neurol. 2009; 51(8): 580-92. doi: 10.1111/j.1469-8749.2009.03351.x. PMID: 19549202.

42) Hirayama S, Hamazaki T, Terasawa K. Effect of docosahexaenoic acid-containing food administration in symptoms of attention-deficit hyperactivity disorder-a placebo-controlled double-blind study. Eur J Clin Nutr. 2004; 58(3): 467-73. doi: 10.1038/sj.ejcn.1601830. PMID: 14985685.

43) Sinn N, Bryan J. Effect of supplementation with polyunsaturated fatty acids and micronutrients on learning and behavior problems associated with child ADHD. J Dev Behav Pediatr. 2007; 28(2): 82-91. doi: 10.1097/01.dbp.0000267558.88457.a5. 